\title{
A systemic model of the sustainable urban tourism insertion in the digital, smart and knowledge city of Mexico City
}

L. E. Romero-García, R. Tejeida-Padilla, A. G. Ramírez-Gutiérrez \& O. Morales-Matamoros

Systems Engineering, Instituto Politécnico Nacional, México

\begin{abstract}
The aim of this paper is to propose a systemic model for the urban tourism insertion in the Digital, Smart and Knowledge City (DSKC) of Mexico City (CDMX) due to the recent and considerable economic importance of this kind of tourism in innovative and competitive cities. Based on this understanding, a diagnosis of the urban tourism role in the DSKC of CDMX was developed by using the systems thinking. Therefore, the Soft Systems Methodology (SSM) was applied, because of its holistic vision, and the technological and social components it involves. The Strategic Direction Model (SDM) was also used in a complementary and parallel way to the SSM. The findings allowed us to detect, among other aspects, the problem situations such as the inexistence of a document which contains the development of the DSKC, and the lack of articulation between the components of the urban tourism and the DSKC. For that reason, some elements were established in order to design a conceptual model. This research finishes by using the Viable System Model (VSM), to validate this construct and, at the same time, provide it with substantial elements, such as innovation, ICT, sustainability, and accessibility, in which tourism and cities have been immersed recently.
\end{abstract}

Keywords: systems science, urban tourism, SSM, VSM, SNA. 


\section{Introduction}

Tourism is one of the main sectors which promotes the economy anywhere there is touristic vocation. However, nowadays, it is necessary for touristic destinations to accomplish certain guidelines which allow them to fulfil the touristic practice in a sustainable [1], safe, and accessible way, among others [2]. These aspects become challenges for big cities because of their overpopulation and the problems it causes. Nevertheless, if well-defined strategies and objectives are designed and stablished, such problems can become opportunities and, thus, can be overcome [3], leading to the construction of innovative and competitive cities. Under this context, tourism and cities are more immersed within the new trends by using and applying Information and Communications Technologies (ICTs) bringing changes in two aspects: i) in tourists' preferences and needs, who are more informed and become more exigent at the time of their visit and; ii) cities adequacy under urban landscape patterns which will make them more attractive and competitive.

This way, urban tourism as well as the cities' new models such as the digital, and the smart ones, among others, become key elements which deal with new trends, citizens and tourists demands, as well as resolve the re-urbanization of big cities. Santander, among other bigger Spanish cities, which were recently constituted as smart cities [4], they have benefited from linking their city model with urban tourism implementation; leading Spain to be first place in the Travel and Tourism Competitiveness Ranking [5]. At the same time, urban tourism represents the $25 \%$ of Spain tourism and has become a priority strategy for the country [6].

For Mexico City (CDMX, in Spanish), which is one of the most visited destinies in Mexico and Latin America, the local government (Gobierno del Distrito Federal (GDF)) has as a priority to promote and encourage health tourism, to enhance ecotourism, and to consolidate cultural and business tourism; which, according to Ashworth and Page [7] and UNWTO [8], it implicitly talks about urban tourism since this offers certain plurality in its offer, allowing the urban tourist to perform a wide and ample range of touristic activities within a city. At the same time, the GDF wants to turn CDMX into a Digital, Smart and Knowledge City (DSKC). If these situations are achieved, urban tourism can be inserted in the design of DSKC so that the GDF can take advantage of its objectives, and as a result, similar benefits can be reached to the ones in Santander, Barcelona, Madrid, among others $[4,9]$.

As a result of what has been explained, this research diagnosed the viability of inserting urban tourism in DSKC-CDMX applying the first three stages of the Soft Systems Methodology (SSM) [10] on one side and, on the other side the Strategic Direction Model (SDM) [11]. Both tools were used to detect conflicts which make the study system inefficient.

Based on this diagnosis, the following two steps of the SSM were developed in order to design a conceptual model which would allow to insert urban tourism in the DSKC-CDMX, and finally, to validate this conceptual model with the reality applying the Viable System Model (VSM) [12, 13], so as to test how efficient and 
viable the developed conceptual model can be and, this way, make sure urban tourism is inserted in DSKC-CDMX.

\section{Study area and methodology}

\subsection{Study area}

The capital city, CDMX, is located in the Metropolitan Area of the Valley of Mexico (MAVM). This area was inhabited by 20,843 million people in 2014; being CDMX where most of those people has settled in, which it makes it one of the biggest and most density populated cities in the world, according to UN [14]. CDMX is conformed by 16 municipalities, being Cuauhtemoc one of the most important. It is considered to be the seventh National Economy because of its infrastructure; commercial, cultural, financial and political activities; as well as its urban corridors specialized on tertiary activities. Regarding tourism, the municipality works on the promotion of 7 local tourism zones. From these zones, Zone 1 (Historical Downtown) and Zone 2 (Alameda, Garibaldi and Bellas Artes) are the most visited $[15,16]$.

According to the elements given by the Internal Factor Evaluation Matrix, which is a tool used in the diagnosis, spatial study limits on Historical DowntownAlameda zones could be stablished. The demarcation was done based on one of the requirements for urban tourism development; that is, to rely on the existing elements in the city [7] which show considerable advances on the development of the DSKC since an already intervened zone is more profitable in the short term than one which is not; moreover, as for technologies implementation, Historical Downtown-Alameda have been more benefited with the ICT's incorporation such as: free Wi-Fi access, events to reduce the digital gap, among others. Regarding the urban image reconstruction, there is the recovery of spaces such as pocket parks (small green areas). This way, 8,125 users downtown, and some other 1,857 in the Alameda Park have been benefited by being simultaneously connected via the free Wi-Fi service [17].

\subsection{Methodology}

The SSM by Checkland [10] was applied for the development of the diagnosis because of the holistic vision it handles, and because it encloses technological and social components. For the development of the second stage of the SSM, the Social Network Analysis tool (SNA) [18-20] was used, which allowed us to create a pictogram and set the Rich Picture. This way, conflict situations among the elements and agents which conform the system were detected and highlighted. Besides the above, the MDE by David [11] was used in order to reinforce the methodology, which allowed us to make the mission statement of the study system; through the External Factor Evaluation Matrix (EFEM), and the Internal Factor Evaluation Matrix (IFEM), we corroborated the weakness and threats found in the Rich Vision, as well as the strengths and opportunities which, within the Rich Vision, cannot be easily perceived. Afterwards, the SWOT matrix was built 
with the success and the failure key factors of the EFEM and IFEM. This matrix helped us structure the necessary strategies, which could be feasible to implement in the short term, in order to accomplish the system's mission. Finally, based on the findings obtained in the diagnosis, the proposal of an urban tourism insertion in the DSKC-CDMX conceptual model was built, as well as its validation by using the VSM by Beer [12].

\section{Findings}

\subsection{Current situation of the study object}

Through the diagnosis made over the role of urban tourism in the DSKC-CDMX project, it was found that there is a strong disarticulation between both parts; that is, urban tourism is not considered in the DSKC-CDMX project and, in the touristic sector, the DSKC is not presented. Therefore, neither of them is taking advantage of the elements they offer for mutual benefit or development. This causes some others problems, which are the conflict situations detected in the Rich Vision (Figure 1). Once the system is designed, along with the elements it is integrated by, and the interrelations are stablished, one can detect: i) the links with some kind of problematic (shown in semi-thick lines), and ii) the non-existent links (thick lines) which, because of their condition, are catalogued within this kind of situations. Some of the problems found were:

1. Cuauhtémoc municipality, tourism secretaries (local and federal), and the GDF perceive only part of everything the urban tourism is about. Therefore, it is identified as a non-existent link. We believe that this type of tourism must give a range of diversified and innovative urban offer, mainly through what already exists, and which assists with the needs of the people who perform the touristic practice $[7,8,21]$. In this sense, we conclude that urban tourism must offer: i) products, such as tours within the destiny using virtual reality, augmented reality, video mappings, and holograms; ii) spaces: safe, accessible, passable, sustainable and maintainable, with a sustainable touristic plant which applies environmentally friendly measures such as solar cells, reuse of blankets in catering facilities, wastewater treatment plant, among others and; iii) services, such as the service providers professionalization, as well as cultural, social and environmental protection training for the citizens, free $\mathrm{Wi}$ Fi access, online booking, mobile applications, touristic location apps, substantial content in landmarks using the heritage interpretation tool, which will generate knowledge and, at the same time, meaningful and transcendental experiences for the one who access it [22-24]. All these under the active participation of agents and elements of the system.

2. The GDF lacks a document which explicitly expresses what the DSKC is. There is only a version of the governmental management in the years 20062012 related to the Digital and Knowledge City, which is why it is catalogued as a non-existent link. This way, a defining concept is proposed: the DSKC is the dynamic urban space which is conformed by the interrelation among the digital, the smart, and the knowledge elements under an organized society 
structure formed by the active participation of the government, enterprises, universities, organism, citizens, and visitors who make use of the different kinds of services, products and offered spaces, in an accessible, sustainable and maintainable environment and, with the incorporation of the ICT's, in order to give creative and innovative solutions (based on knowledge generation) to the problems in the city, to generate well-being for society, and develop a competitive space at worldwide level.

3. In regards to accessibility, only some of the disabilities related to the mobility of the people within the city, by the implementation of ramps, have been assisted. Therefore, it is considered as a link with interrelation conflict. In this sense, the incorporation of elements, which assist the rest of disabilities and vulnerable people, is missing. At the same time, it is necessary to focalize the attention in order to reduce the communication barriers (contents), through the use of the heritage interpretation tool.

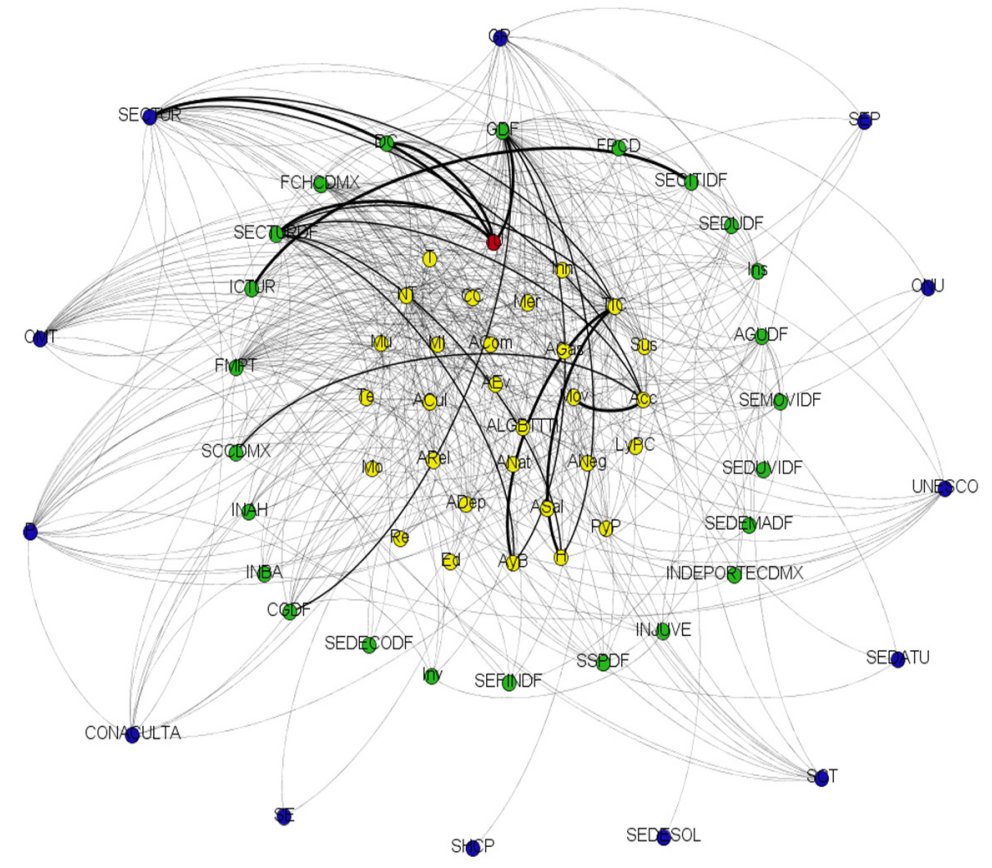

Figure 1: Second stage: problem situation expressed. Rich Vision.

This way, since the incorporation of the urban tourism in the DSKC-CDMX is missing, an approach to the role it has to play in a city like this is given: Tourism, as a humanistic, transdisciplinary, multi-causal, and systemic phenomenon, has as its main goal to generate meaningful and transcendental experiences which will contribute to the integral development of the ones who make it and generate a positive impact in the place to be visited as well as in the place tourists live. Therefore, urban tourism, under the same optic and within the DSKC, has to give 
information in real time about the places to be visited in a city, design and provide constantly innovative products and services in order to add value to the city, and become a knowledge generator with the aim of causing a positive effect within the visited place as well as in the residence of the people who perform the touristic practice. This last aspect is really important because of the economic impact it can have on the societies [25].

On the other hand, through the SDM stages, as a complementary part to the methodology in order to develop the diagnosis, in the EFEM and IFEM, it was detected that the internal and the external evaluation of the study system reached a higher understand, on the one hand, that the study system has enough strengths and opportunities in order to be able to take part in a competitive worldwide environment; whereas, on the other hand, the system is capable of foreseeing, at a certain extent, the effects caused by the threats and weaknesses; all this if adequate strategies are stablished.

As a result, it stands out that the systems thinking in the DSKC design must be considered. In consequence, the need to build and propose a systemic model was detected. This model will allow us to insert each of the urban tourism components in the DSKC in order to give space, products and service proposals in which government authorities, entrepreneurs, professionals, among other agents involved in urban tourism and the DSKC invest, link, create plans to help to solve the city problems, generate meaningful and differentiating experiences, innovate and become competitive; all this, in order to lead to systemic value generation.

\subsection{Design of a conceptual model}

The proposed model shows the urban tourism insertion in the DSKC-CDMX as one of the main sectors which would generate well-being to citizens, tourists, stakeholders, among others.

The urban tourism model structure which is inserted in the DSKC-CDMX (Figure 2) is formed by five systems in the shape of holos which are open to the system in order to interact freely and clearly with the rest of the systems and its environment. The importance of the client, whom the system is aimed at because of its location towards the centre, is emphasized. These systems are conformed by subsystems which, at the same time, are conformed by some others. Each of the five systems is ordered inside out according to the direct impact this can cause to the system in case of failure. Next, each of the system is explained briefly.

The first system, the antropoaxiologic, is proposed as the base system since its main function is to give the humanistic, cultural, and ethical supports to all the agents found inside and affected by the city components. It is composed by elements such as bioethics and social accessibility which have to encounter in the government programs contents, in order to promote the formation of better human beings in relations to themselves, environment, as well as to their peers. With this system, it is aimed to contribute to the reinforcement of the sense of belonging, community and hospitality is promoted; mainly within the citizens.

The second system, the operational, is conformed by two subsystems: of design, and of marketing and sales. As for the design subsystem, this manages the 


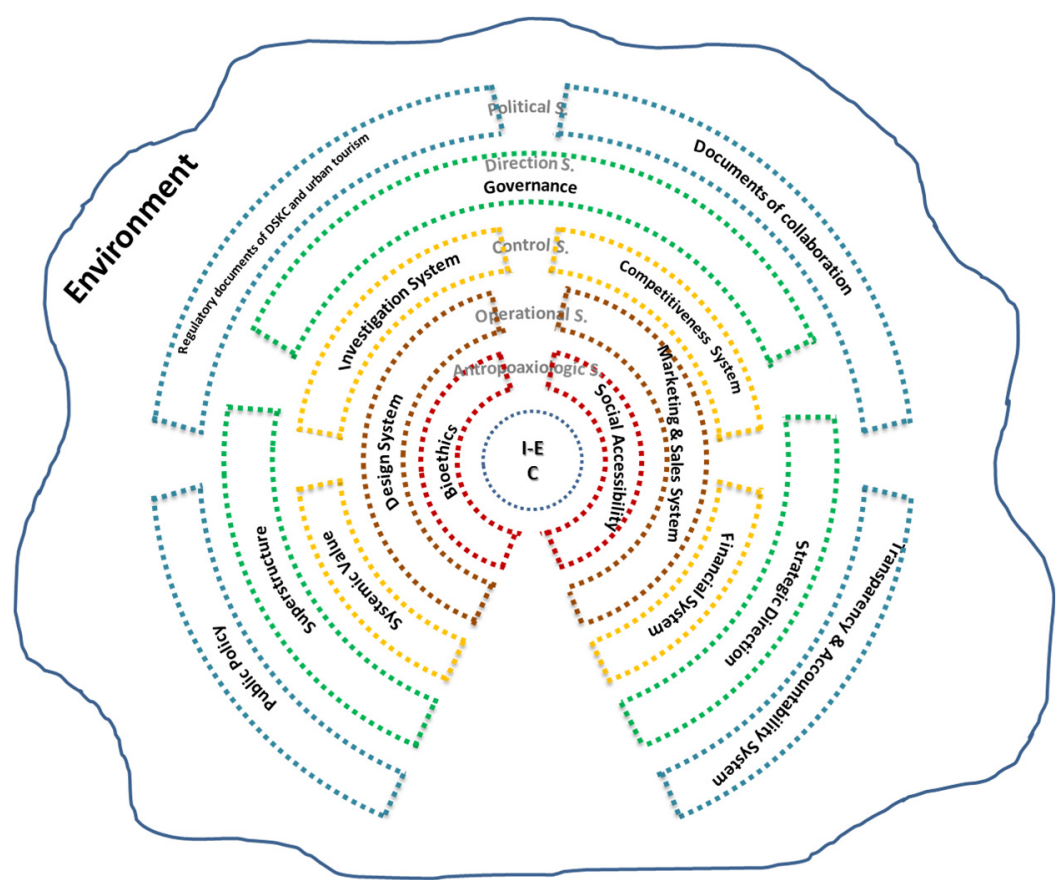

Figure 2: Conceptual model of the urban tourism in the DSKC-CDMX.

optimization of the natural and cultural resources the city has, through governance and bioethics. It also considers urban planning for the rehabilitation of the structure under the landscaping, physical and content accessibility, signaling, sustainability, safe, and innovation parameters in such a way that it contributes to give order and diversity to the spaces. Also, equipment and technological infrastructure must be given through the Internet of Things (IoT) and the Internet of Everything (IoE) so as to generate knowledge and the city sustainability. With this technological part, the development of the city as digital and smart is promoted. This element becomes substantial for the design of the city as well as for their services and products at the moment information arises in real-time and in a more reliable way. In the case of touristic activity, consumption tendencies as well as satisfaction levels of tourists and any who makes use of the city services are given.

As for the marketing and sales subsystem, it has to know the structure as well as the natural and cultural resources the city has in order to promote and spread them at international, national and local level. It is also in charge of diffusing the discounts and offers to make the destiny more attractive and thus, become more likely to be visited. Likewise, by taking advantage of the technological architecture, market studies are made in order to know the tourist' and visitors' new trends. This way, a wide, new, and accessible offer is given based on the generation of meaningful and transcendental experiences which lead to studies about the assurance of products and services qualities. 
The third system, the control, is led by a superstructure such as the GDF and tourism Secretaries under the governance principles, which are: transparency, accountability, active collaboration among actors, networks work, local capacities reinforcement, management efficiency, among others, so that the system works efficiently and effectively.

The fourth system, the direction, will allow authorities to measure, evaluate and, at certain moment, give remedial work to generate systemic value through research coming from the link and interrelation of different agents in the system, such as: academician, businessman, investors, organism (Touristic Competitiveness Institute (ICTUR in Spanish)), citizens, and tourists who, by visiting labs, observatories, and scientific parks, generate quantifiable, accurate, open and manageable information to generate knowledge. This system interacts with the competitiveness subsystem in order to develop the knowledge part of the city, through the professionalization of services providers, government authorities, among others. It also has to promote entrepreneurship, give accessibility to content in tourist places, through the heritage interpretation tool. The hard part of the system is also found, which covers financial aspects conformed by the public sector, semi-public, volunteering and private. To sum up, this system, along with the antropoaxiologic one, must provide with most of the necessary elements for the total system maintenance.

The fifth system, the political, helps create public policy in order to make the system works appropriately. In this case, the creation of a regulatory document of DSKC and urban tourism is necessary. Another document is related to the collaboration between ICTUR and the Science, Technology and Innovation Secretary (SECITIDF in Spanish) due to the disarticulation between both agents, which handle aspects such as: innovation and the ICT's. The transparency and accountability subsystem, with the help of the technical subsystem, are considered because they can provide the necessary elements to give continuity to plans and programs which have been working appropriately and, because of political issues, are discarded. This last aspect helps continue with the development of the digital part.

Under this conceptual model, the interaction among the five systems will allow us to put forward strategies structured through the SWOT matrix. For instance, antropoaxiologic, direction, and operational systems fulfill strategy 1, which is about the reinforcement of the cultural identity and the digital gap rupture among the citizens by taking advantage of the social, transparency and accountability programs of the GDF.

The interaction of the operational, control and direction systems aims at fulfilling strategy 3, which is to diminish the seasonality effect and to increase hotel occupancy by encouraging the stay of local and nearby tourism (MAVM), through the implementation of new products and services which can be offered through urban tourism with the intervention of agents and elements of the system.

The interaction of direction, operational and normative systems, tries to fulfill strategy 5 , which is to digitally back up the plans and programs of the GDF and its municipalities, as well as to upload them to different websites of the government with the collaboration of different sectors and agents, so as to monitor 
the follow-up and continuity of those which are having a positive impact in society, as well as to modify the ones which present a high level of failure in order to reduce corruption and promote citizenship, country and international credibility among citizens within the country and at international level.

Once the conceptual model is stablished, validation by the VSM was made in order to design a systemic model proposal which make the system work effectively.

\subsection{Conceptual model validation through the VSM}

The conceptual model can be contrasted with the reality by using the VSM. Such validation is based on the diagnostic results and from the researcher hermeneutic; to be questioned by the postulates of the system which is conformed by five subsystems highly interrelated among them and their environment which lead to the total system viability; that is, they need to be able to maintain the system identity leading to its survival [26]. This way, the construct is the following:

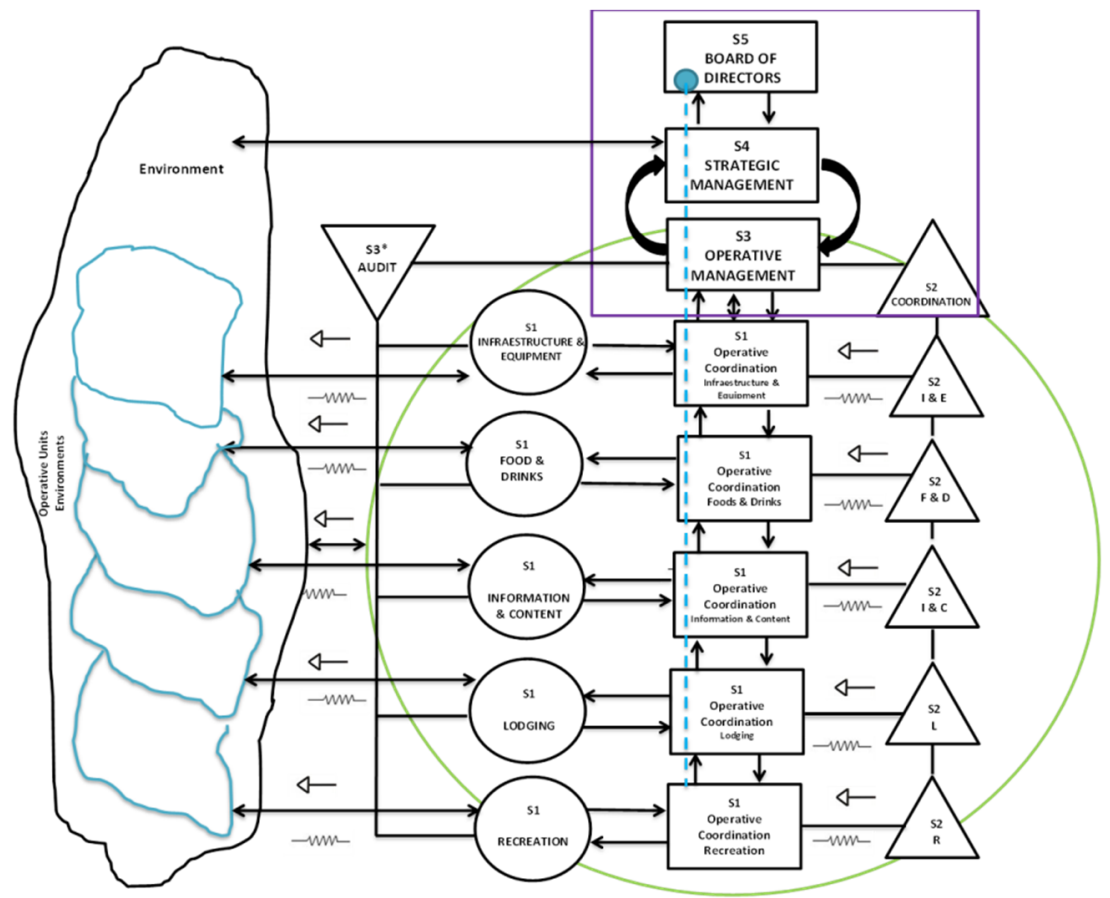

Figure 3: Viable System Model for the urban tourism system, to insert in the DSKC-CDMX.

In Figure 3, a total system and its elements can be appreciated. In a general way, this model is conformed by three basic elements: the environment (amoeba shape), the organization (circle), and the administration (square). From these elements, the five subsystems which conform the model emerge: 1) Operations, 2) 
Coordination, 3) Operative Management, 3*) Audit, 4) Strategic Management, and 5) Board of Directors. For the case of the study system applying the VSM, there are five operational units (small circles) which are in charge of offering tourism products and services to the environment. Each one has its own environment, coordination and regulator in order to keep its identity and ensure its viability. This system is supported by some elements which facilitate the communication in its inside and its outside, which are: a) amplifiers (white arrows), which broader the information scope; b) attenuators (spring shape), which allow agents to get, from all the information in the environment, only the one which is useful for the system; c) the algedonic channel (dotted line), which is a strategic channel that allows urgent information to reach subsystem 5, if necessary, to timely decision making and; d) the Homeostat (thick black arrow), which is the controller channel between subsystems 3 and 4, to coordinate the inside and outside information of the system.

When these five subsystems are contrasted with the reality, the coordination and operation subsystems, which do not currently exist, were identified. Therefore, these subsystems, together with the auditing one are incorporated to the conceptual model in order to make it viable. In this research, we focused only in the coordination subsystem because it provides the necessary elements to create a positive impact in the study system. The coordination subsystem is conformed by the elements of information systems, products and events programs, tasks programming planning, coordination teams, and operation standards; and it is in charge of the holistic operation of the operational units to prevent conflict situations from arising among each of them. In many cases, the non-existence of this subsystem in the reality causes the lack of links, making the system fail, as they were found through this research.

This way, by contrasting the conceptual model with the VSM, the design of the systemic model of urban tourism insertion in the DSKC-CDMX, in which not only sustainable part is taken into account, but also the innovation and accessibility, among others, in order to achieve the maintainability of the system, that is its viability.

\section{Conclusions}

This research concludes with a systemic model proposal, which has a high level of reliability because it is designed under the Systems Thinking, and the Strategic Direction; leading to provide solutions to the conflict situations as well as to set the links where there were no before.

Regarding the VSM used to validate the proposal model, it allow us to verify the way the subsystems and agents of the system operate, and how their interrelations among them and their environment must be to be efficient and viable to achieve its mission and objectives.

In this sense, the systemic construct proposed is easy to apply because of its singular characteristics, such as: i) flexibility, because it does not need many resources, as others do and; ii) robustness, to replicate the model in other zones 
and municipalities of the CDMX; cities and states; taking into account their different particularities, obtained through the diagnosis.

Therefore, with this research we are trying to contribute to state of the art in urban tourism in digital, smart and knowledge cities, to provide solutions to problems with social and technical content.

\section{References}

[1] Cumo, F., Astiaso García, D., Stefanini, V. \& Tiberi, M., Technologies and strategies to design sustainable tourist accommodations in areas of high environmental value not connected to the electricity grid. International Journal of Sustainable Development and Planning, 10(1), pp. 20-28, 2015.

[2] Edwards, D., Griffin, T. \& Hayllar, B., Urban tourism research: developing an agenda. Annals of Tourism Research, 35(4), pp. 1032-1052, 2008.

[3] Jin, J., Gubbi, J., Marusic, S. \& Palaniswami, M., An Information Framework for Creating a Smart City Through Internet of Things. Internet Things Journal, IEEE, 1(2), pp. 112-121, 2014.

[4] Sanchez, L., Muñoz, L., Galache, J.A., Sotres, P., Santana, J.R., Gutierrez, V., Ramdhany, R., Gluhak, A., Krco, S., Theodoridis, E. \& Pfisterer, D., SmartSantander: IoT experimentation over a smart city testbed. Computer Networks, 61, pp. 217-238, 2014.

[5] WEF, The Travel \& Tourism Competitiveness Report 2015, World Economic Forum: Geneva, 2015.

[6] EXCELTUR, UrbanTUR 2012. Monitor de competitividad turística en los destinos españoles, Madrid, 2013.

[7] Ashworth, G. \& Page, S.J., Urban tourism research: Recent progress and current paradoxes. Tourism Management, 32(1), pp. 1-15, 2011.

[8] UNWTO, Global Report on City Tourism AM Reports: Volume six, World Tourism Organization: Madrid, 2012.

[9] Anthopoulos, L.G. \& Vakali, A., Urban Planning and Smart Cities: Interrelations and Reciprocities. The Future Internet $S E-16$. Lecture Notes in Computer Science vol 7281, eds. F. Álvarez, F. Cleary, P. Daras, J. Domingue, A. Galis, A. Garcia, A. Gavras, S. Karnourskos, S. Krco, M-S. Li, V. Lotz, H. Müller, E. Salvadori, A-M. Sassen, H. Schaffers, B. Stiller, G. Tselentis, P. Turkama \& T Zahariadis, Springer: Berlin Heidelberg, pp. 178-189, 2012.

[10] Checkland, P., Systems Thinking, Systems Practice, Wiley: London, 1981.

[11] David, F.R., How companies define their mission. Long Range Planning, 22(1), pp. 90-97, 1989.

[12] Beer, S., The Viable System Model: Its Provenance, Development, Methodology and Pathology. The Journal of the Operational Research Society, 35(1), pp. 7-25, 1984.

[13] Pérez Ríos, J., Diseño y Diagnóstico de Organizaciones Viables: Un Enfoque Sistémico, Iberfora 2000: Valladolid, 2008. 
[14] UN, World Urbanization Prospects: The 2014 Revision, Highlights (ST/ESA/SER.A/352), United Nations, Department of Economic and Social Affairs, Population Division: New York, 2014.

[15] Fideicomiso Centro Histórico de la Ciudad de México, Reglas de operación del fideicomiso centro histórico de la Ciudad de México, Ciudad de México, 2007.

[16] SECTURDF, Programa Sectorial de Turismo del Distrito Federal 20132018, SECTURDF: Ciudad de México, 2014.

[17] GDF, Segundo Informe de Gobierno del Distrito Federal (2013-2014), Gobierno del Distrito Federal (GDF): Ciudad de México, 2014.

[18] Freeman, L.C., Centrality in social networks: conceptual clarification. Social Networks, 1(3), pp. 215-239, 1979.

[19] Wasserman, S. \& Faust, K., Social Network Analysis: methods and applications, Cambridge University Press: New York, 1994.

[20] Hanneman, R.A. \& Riddle, M. Concepts and measures for basic network analysis. The SAGE Handbook of Social Network Analysis, eds. J. Scott \& P J. Carrington, SAGE: London, pp. 340-369, 2011.

[21] Bramwell, B., User satisfaction and product development in urban tourism. Tourism Management, 19(1), pp. 35-47, 1998.

[22] Espinosa Ruiz, A., La accesibilidad física e intelectual de todo tipo de público al patrimonio cultural (I). Boletín Interpretación, 6, pp. 13-15, 2002.

[23] Tilden, F., La interpretación de nuestro patrimonio, Asociación para la Interpretación del Patrimonio: Sevilla, 2006.

[24] Beck, L. \& Cable, T.T., Interpretation for the 21st century: Fifteen guiding principles for interpreting nature and culture, Sagamore publishing, 1998.

[25] Rohrbach, D. The development of knowledge societies in 19 OECD countries between 1970 and 2002. Social Science Information, 46(4), pp. 655-689, 2007.

[26] Schwaninger, M., Intelligent organizations: Powerful models for systemic management, Springer-Verlag: Berlin Heidelberg, 2008. 